\title{
Article \\ Circulating Microvesicle-Associated Inducible Nitric Oxide Synthase Is a Novel Therapeutic Target to Treat Sepsis: Current Status and Future Considerations
}

\author{
Robert J. Webber ${ }^{1, *}$, Richard M. Sweet ${ }^{2,3}$ and Douglas S. Webber ${ }^{1}$ \\ Research \& Diagnostic Antibodies, Las Vegas, NV 89117, USA \\ School of Medicine, University of California, San Francisco, CA 94143, USA \\ Renal Department, Zuckerberg San Francisco General Hospital, San Francisco, CA 94110, USA \\ Correspondence: rjwebber@rdabs.com
}

check for updates

Citation: Webber, R.J.; Sweet, R.M.; Webber, D.S. Circulating

Microvesicle-Associated Inducible

Nitric Oxide Synthase Is a Novel

Therapeutic Target to Treat Sepsis: Current Status and Future

Considerations. Int. J. Mol. Sci. 2021,

22, 13371. https://doi.org/10.3390/ ijms222413371

Academic Editor: Alessandro Russo

Received: 19 November 2021

Accepted: 10 December 2021

Published: 13 December 202

Publisher's Note: MDPI stays neutral with regard to jurisdictional claims in published maps and institutional affiliations.

Copyright: (c) 2021 by the authors. Licensee MDPI, Basel, Switzerland. This article is an open access article distributed under the terms and conditions of the Creative Commons Attribution (CC BY) license (https:// creativecommons.org/licenses/by/ $4.0 /)$

\begin{abstract}
To determine whether mitigating the harmful effects of circulating microvesicle-associated inducible nitric oxide (MV-A iNOS) in vivo increases the survival of challenged mice in three different mouse models of sepsis, the ability of anti-MV-A iNOS monoclonal antibodies (mAbs) to rescue challenged mice was assessed using three different mouse models of sepsis. The vivarium of a research laboratory Balb/c mice were challenged with an $\mathrm{LD}_{80}$ dose of either lipopolysaccharide (LPS/endotoxin), TNF $\alpha$, or MV-A iNOS and then treated at various times after the challenge with saline as control or with an anti-MV-A iNOS mAb as a potential immunotherapeutic to treat sepsis. Each group of mice was checked daily for survivors, and Kaplan-Meier survival curves were constructed. Five different murine anti-MV-A iNOS mAbs from our panel of 24 murine anti-MV-A iNOS mAbs were found to rescue some of the challenged mice. All five murine mAbs were used to genetically engineer humanized anti-MV-A iNOS mAbs by inserting the murine complementaritydetermining regions (CDRs) into a human $\operatorname{IgG}_{1 \text {,kappa }}$ scaffold and expressing the humanized $\mathrm{mAbs}$ in $\mathrm{CHO}$ cells. Three humanized anti-MV-A iNOS mAbs were effective at rescuing mice from sepsis in three different animal models of sepsis. The effectiveness of the treatment was both time- and dose-dependent. Humanized anti-MV-A iNOS $\mathrm{rHJ}$ mAb could rescue up to $80 \%$ of the challenged animals if administered early and at a high dose. Our conclusions are that MV-A iNOS is a novel therapeutic target to treat sepsis; anti-MV-A iNOS mAbs can mitigate the harmful effects of MV-A iNOS; the neutralizing $\mathrm{mAb}$ 's efficacy is both time- and dose-dependent; and a specifically targeted immunotherapeutic for MV-A iNOS could potentially save tens of thousands of lives annually and could result in improved antibiotic stewardship.
\end{abstract}

Keywords: sepsis; therapeutic target; inducible nitric oxide synthase; iNOS; microvesicles; nanoparticles

\section{Introduction}

Previously, we described the development and characterization of our panel of 24 murine anti-iNOS monoclonal antibodies (mAbs) including their potential use to detect the onset of sepsis [1]. Sepsis is an enormous medical problem globally [2]. The current sepsis definition, Sepsis-3, is now defined as life-threatening organ dysfunction caused by a dysregulated host response to infection [3]. Over the past several years, the need to rethink therapeutics to treat sepsis and diagnostic tests to identify individuals at a high risk of becoming septic has been recognized [4-6]. As is widely known, more than two dozen phase 3 clinical trials on numerous candidate therapies for sepsis have failed during the past $30+$ years $[4,5]$. At present, not a single specifically targeted drug is approved for the treatment of sepsis. Likewise, numerous candidate biomarkers have been proposed to detect sepsis, but only one, plasma inducible nitric oxide synthase (iNOS), appears to be specific for the onset of sepsis [6,7]. Our discovery of the normally intracellular enzyme iNOS circulating in the blood in microvesicles and its relationship to the sepsis 
pathology as both a specific biomarker for the onset of sepsis and a novel therapeutic target to treat sepsis $[6,8]$ led us to develop a recombinant humanized anti-microvesicle associated (MV-A) iNOS IgG $\mathrm{G}_{1, \text { kappa }}$ monoclonal antibody $(\mathrm{rHJ} \mathrm{mAb})$ as an efficacious candidate immunotherapeutic [8].

Recently, the number of deaths worldwide involving sepsis was estimated to be more than 11 million annually, $19.2 \%$ of all deaths each year [2]. This estimate was made based upon the analysis of millions of death certificates from 2017. It has also been recently reported that almost all deaths due to the COVID-19 pandemic resulted from sepsis [9-11]. The in-hospital and long-term economic and societal burden of sepsis makes it one of the most pressing patient care issues worldwide. However, despite intense research efforts and the investment of billions of dollars over the past 30+ years by pharmaceutical and biotechnology companies and by government research institutes worldwide, a targeted therapy to treat sepsis has still not been developed [4,5].

The US Department of Health and Human Services (DHHS) has estimated the direct cost of sepsis to the US healthcare system to be greater than USD 60 billion annually [12-14]. Health economic analyses have estimated that the direct cost of sepsis is only $28 \%$ of its total cost to society-the other $72 \%$ of its cost is due primarily to lost productivity from individuals who either die of sepsis or are disabled and are unable to provide for themselves and their families after surviving an episode of sepsis [15-17].

As the sepsis pathology progresses, organ dysfunction often occurs and deteriorates into multiple organ failure and death [18-20]. Sepsis is estimated to be involved in up to $50 \%$ of all hospital deaths, and morbidity and mortality remain unacceptably high in septic patients mainly due to the lack of a specific and targeted treatment [21-23]. Additionally, mortality has been reported to increase approximately $5 \%$ per year for the first five years after discharge due to the long-term health complications of sepsis [24,25].

The current definition of sepsis [3], Sepsis-3, is based upon an individual patient's SOFA score (or quick SOFA score, qSOFA) and superseded the prior definition, now called Sepsis-2, that was based upon the SIRS criteria and a confirmed or suspected infection [26]. Over the last few years, numerous research groups have demonstrated that when the Sepsis-2 and Sepsis-3 definitions are applied to actual patients enrolled in clinical studies, the two definitions define different septic patient subpopulations, with only a partial overlap $[27,28]$. Because a spectrum of symptoms exists, many septic patients do not display the same or similar symptoms. Thus, even defining what sepsis is (or is not) has been a challenge and has hindered the development of a specific therapeutic $[3-5,18,19,26,29]$.

The clinical need for a specific and efficacious therapeutic to treat sepsis is widely recognized and well documented $[3-5,18,19,21,26]$. Most clinicians in this field agree that a targeted therapy for the sepsis pathology would be a major medical breakthrough and would vastly improve best practices treatment and care for septic patients. An effective targeted therapeutic for sepsis should decrease mortality and morbidity and save healthcare systems worldwide billions of dollars annually [12-16].

For the last few years, our research team has been investigating a novel form of the normally intracellular iNOS enzyme that is not customarily found in blood. However, during the onset of sepsis, iNOS is found in circulating microvesicle (MV) nanoparticles as microvesicle-associated iNOS (MV-A iNOS) in whole blood and plasma samples [6,7]. Based upon our data and data from independent investigators [30-32], circulating MV-A iNOS appears to play a major role in the onset of the sepsis cascade by producing toxic quantities of $\mathrm{NO}$ in sites distal from the site of an infection and thereby causing cellular damage and organ dysfunction. Data presented herein demonstrate that MV-A iNOS is a validated new therapeutic target for sepsis and that anti-MV-A iNOS mAbs can effectively stop the harmful systemic effects caused by circulating MV-A iNOS. Thus, a recombinant humanized anti-MV-A iNOS mAb can be the first effective immunotherapeutic drug to treat sepsis and to meet this significant unmet medical need. 


\section{Materials and Methods}

\subsection{Radio-Labeling $M V-A$ iNOS as Tracer}

To determine the half-life of MV-A iNOS in blood and whether the uptake of MV-A iNOS by organs is altered by lipopolysaccharide (LPS/endotoxin), MV-A iNOS was purified by centrifugation, followed by column chromatography. The fractions containing the purified MV-A iNOS were pooled, dialyzed, concentrated, and radio-iodinated using iodogen and carrier-free $\mathrm{Na}^{125} \mathrm{I}$. The ${ }^{125}$ I-labeled MV-A iNOS was used to determine the $\mathrm{T} \frac{1}{2}$ of MV-A iNOS in blood and was also used in a series of pulse-chase experiments to determine its uptake by different organs.

\section{2. $T \frac{1}{2}$ determination for ${ }^{125} \mathrm{I}-\mathrm{MV}$-A iNOS in Blood}

Five mice were injected IV with $4 \times 10^{6} \mathrm{dpm}$ of ${ }^{125} \mathrm{I}-\mathrm{MV}$-A iNOS, and at time points, a $50 \mu \mathrm{L}$ blood sample was collected from the tail vein of each mouse in hematocrit tubes. The blood was centrifuged, and an aliquot of plasma was counted in a scintillation well gamma counter. The data were plotted, and the half-life was calculated.

\subsection{Tissue Distribution of $M V$-A iNOS}

Eight groups of three mice $(\mathrm{N}=3)$ were primed with a sub-lethal dose of LPS or given a saline injection as controls; $4 \mathrm{~h}$ later, they were injected IV with $4 \times 10^{6} \mathrm{dpm}$ of ${ }^{125} \mathrm{I}-\mathrm{MV}-\mathrm{A}$ iNOS; and $60 \mathrm{~min}$ later euthanized by ether anesthesia. Before dissection, each animal was subjected to transcardial whole-body perfusion with $20 \mathrm{~mL}$ of sterile saline to remove blood from all the organs. Heart, liver, intestines, and spinal cord were rapidly dissected, weighed, and counted for their content of ${ }^{125} \mathrm{I}$ on a scintillation well gamma counter. The results for each mouse as disintegrations per minute $(\mathrm{dpm}){ }^{125} \mathrm{I}$ per $\mathrm{mg}$ tissue $(\mathrm{dpm} / \mathrm{mg})$ was calculated for each organ. The average $\mathrm{dpm} / \mathrm{mg}$ was then calculated for each organ for all groups.

\subsection{Genetically Engineered Recombinant Humanized Anti-MV-A iNOS Monoclonal Antibodies (mAbs)}

After determining that five of the mAbs in our panel of 24 murine anti-iNOS mAbs [1] possessed in vivo neutralizing activity, as judged by their ability to rescue challenged animals from death in three different animal models of sepsis, each was humanized by inserting the mouse CDRs into human $\operatorname{IgG}_{1}$ heavy chains and human kappa light chains. The humanized $\mathrm{mAbs}$ were stably transfected into and expressed as recombinant humanized IgG $\mathrm{I}_{1, \mathrm{kappa}}$ monoclonal antibody in $\mathrm{dhfr} \mathrm{r}^{-} \mathrm{CHO}$ cells. After a series of cloning, selection, and amplification rounds, each of the stable $\mathrm{rCHO}$ cell lines was cryopreserved as a master cell bank. All the recombinant humanized anti-MV-A iNOS mAb clones were tested for in vivo neutralization of MV-A iNOS in our mouse bioassay $[8,33]$.

\subsection{Kaplan-Meier Survival Curves}

To determine whether $\mathrm{rHJ} \mathrm{mAb}$ was effective as a candidate treatment for sepsis, groups of mice were injected IV with LPS at $6.0 \mathrm{mg} / \mathrm{kg}$ ( $a n$ LD 80 dose of LPS) and 0,2 , and $6 \mathrm{~h}$ later were treated with either saline (control) or low-dose $\mathrm{rHJ} \mathrm{mAb}$ (125 ng/gm body weight) or high-dose $\mathrm{rHJ} \mathrm{mAb}(1.25 \mu \mathrm{g} / \mathrm{gm}$ body weight). The number of mice surviving was checked daily for 7 days, and the results were plotted as Kaplan-Meier survival curves. Two additional mouse models of sepsis were also utilized: one used an $\mathrm{LD}_{80} \mathrm{IV}$ dose of $\mathrm{TNF} \alpha$, and the other used an $\mathrm{LD}_{80}$ IV dose of MV-A iNOS [8,33].

\subsection{Potential Drug Interference}

Seven commonly administered anti-infectives were tested by ELISA for their potential interference with the binding of our anti-MV-A iNOS mAb to MV-A iNOS spiked into normal human plasma samples. The recommended doses were obtained from the package insert for each drug. The $1 \times$ plasma concentration was calculated assuming it was being administered to a $50 \mathrm{~kg}$ person with a plasma volume of $1900 \mathrm{~mL}$. Each drug was tested 
in triplicate for its effect on spiked plasma samples containing $250 \mathrm{pgm}$ of MV-A iNOS. The anti-infectives tested were Caspofungin at $36.9 \mu \mathrm{g} / \mathrm{mL}$, ceftriaxone at $528 \mu \mathrm{g} / \mathrm{mL}$, levofloxacin at $264 \mu \mathrm{g} / \mathrm{mL}$, meropenem at $264 \mu \mathrm{g} / \mathrm{mL}$, metronidazole benzoate at $264 \mu \mathrm{g} / \mathrm{mL}$, piperacillin/tazobactam at $1.78 \mathrm{mg} / \mathrm{mL}$, and vancomycin at $528 \mu \mathrm{g} / \mathrm{mL}$.

\section{Results}

Previously, our team reported that while conducting clinical studies on inducible nitric oxide synthase (iNOS) as a potential new blood biomarker for the onset of sepsis, it was discovered that the iNOS in blood was exclusively contained in circulating microvesicle nanoparticles and was only present in the blood of individuals who were already septic or who would become septic in the next 24 to $48 \mathrm{~h}[6,7]$. A name for the circulating iNOS in blood microvesicles was created-microvesicle-associated iNOS (MV-A iNOS) - since iNOS in blood appears to be present exclusively in circulating microvesicles and not as a freely soluble protein $[6,7]$.

After discovering MV-A iNOS, experiments were performed to determine its halflife in blood and its tissue and organ distribution. Based upon the disappearance of IV-administered ${ }^{125} \mathrm{I}-\mathrm{MV}-\mathrm{A}$ iNOS from blood, the half-life of MV-A iNOS was found to be biphasic. The fast component has a $\mathrm{T} \frac{1}{2}$ of $11 \mathrm{~min}$, and the slow component has a $\mathrm{T} \frac{1}{2}$ of $18 \mathrm{~h}$. To compare the changes in the distribution of MV-A iNOS with tissues and organ that resulted from a non-lethal dose of LPS, the results of the pulse-chase experiments for the heart, spinal cord, intestines, and liver were normalized to the value found for the saline-treated control animals for each organ individually (Table 1). Statistically significant differences were calculated by Student's $t$-test, and P values less than 0.05 are considered significant. In the heart, LPS treatment resulted in an $86 \%$ increase in the amount of ${ }^{125}$ I-MV-A iNOS taken-up as compared with the saline-treated group. In the spinal cord, LPS treatment resulted in an $87 \%$ increase in the amount of ${ }^{125}$ I-MV-A iNOS taken-up as compared with the saline-treated group. In the intestines, treatment with LPS resulted in a more than doubling of the amount of ${ }^{125} \mathrm{I}-\mathrm{MV}-\mathrm{A}$ iNOS taken-up as compared with the saline-treated group. However, in the liver, no discernible change was found in the amount of ${ }^{125} \mathrm{I}-\mathrm{MV}-\mathrm{A}$ iNOS that was up taken following LPS treatment as compared with the saline control group.

Table 1. Organ Uptake of ${ }^{125}$ I-MV-A iNOS After an LPS Challenge in Mice Normalized against Saline Controls.

\begin{tabular}{cccc}
\hline & & Normalized DPM & \\
\hline Organ $\mathbf{I} / \mathbf{m g}$ Tissue \\
\hline Heart & Saline Only & Saline + LPS & $p$ Value * \\
\hline Spinal Cord & $100.0 \%$ & $186.4 \%$ & $p<0.05$ \\
\hline Intestines & $100.0 \%$ & $187.1 \%$ & $p<0.05$ \\
\hline Liver & $100.0 \%$ & $201.1 \%$ & $p<0.05$ \\
\hline
\end{tabular}

* A difference of $p<0.05$ is considered statistically significant.

In order to determine whether any of our murine anti-iNOS mAbs possessed in vivo neutralizing activity, our panel of 24 anti-iNOS monoclonal antibodies [1] was screened for their individual ability to neutralize in vivo the lethal effects of circulating MV-A iNOS in our mouse bioassay $[8,33]$. Five of the murine anti-iNOS mAbs in our panel were found to be effective at rescuing mice from a lethal challenge of MV-A iNOS (Figure 1). All five of the in vivo neutralizing murine anti-MV-A iNOS mAbs were humanized by genetically engineering techniques. All the humanized anti-MV-A iNOS clones were tested for in vivo neutralization of MV-A iNOS. 


\section{Neutralization of Microvesicle- Associated iNOS by Anti-iNOS mAbs}

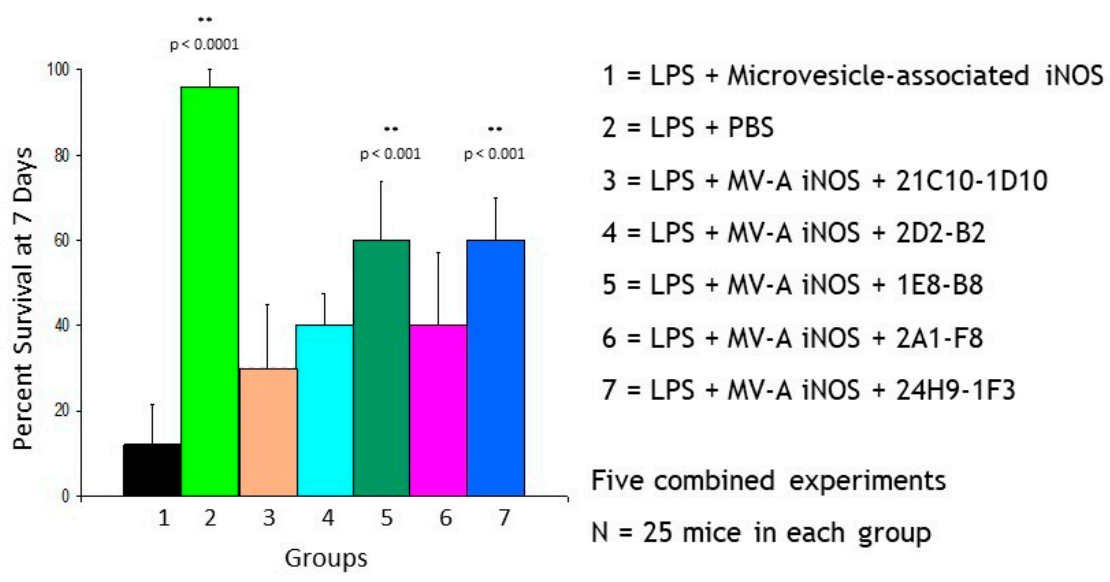

** Statistically significant differences as compared to Group \#1

Figure 1. These are the combined data from five different experiments in which we tested all our murine anti-iNOS mAbs. Mice were dosed with LPS at $2 \mathrm{mg} / \mathrm{kg}$ at time zero and that was followed with a dose of MV-A iNOS at $4 \mathrm{~h}$. At this dose of MV-A iNOS, 88\% (22 of 25 died) of the challenged animals died of sepsis. As Lane \#2 shows, if saline is injected at $4 \mathrm{~h}$ instead of MV-A iNOS, then more than 95\% (24 of 25 lived) of the animals lived because a very low dose of LPS was used to prime the animals. Many of the murine anti-iNOS mAbs in our panel [1] did not rescue mice from death by sepsis since they did not neutralize the lethal effects of MV-A iNOS in vivo even though they all bound to iNOS. However, intervention with the anti-iNOS mAbs illustrated in Lanes \# 3-7 did have a beneficial effect since they rescued some of the challenged mice from death by sepsis by stopping the sepsis cascade in these animals. The anti-iNOS mAbs depicted in Lanes \# 3-7 were selected for continued investigation as potential candidate therapeutics to treat the sepsis pathology. The mouse monoclonal antibody secreting hybridoma cell lines were used to construct recombinant humanized anti-MV-A iNOS mAbs. Humanized anti-MV-A iNOS J mAb $(\mathrm{rHJ} \mathrm{mAb})$ is our lead immunotherapeutic candidate to treat sepsis.

Three recombinant humanized anti-MV-A iNOS mAbs-rHA mAb, rHD mAb, and $\mathrm{rHJ} \mathrm{mAb}$ - were found to rescue mice from a lethal challenge in three different mouse models of sepsis: an LPS model, a TNF $\alpha$ model, and our in-house MV-A iNOS model of sepsis [33]. As is illustrated by the Kaplan-Meier survival curves (Figure 2) for the LPS mouse model using the $\mathrm{rHJ} \mathrm{mAb}$ intervention, three recombinant humanized anti-MV-A iNOS mAbs were shown to have some efficacy. Their effectiveness was both dose- and time-after-challenge-dependent-the higher the dose and the earlier it was administered, the more effective each humanized anti-MV-A iNOS $\mathrm{mAb}$ was at rescuing mice from death by sepsis. However, only rHJ mAb could rescue up to $80 \%$ of the challenged animals from death by sepsis if administered within the first two hours after the LPS challenge.

None of the seven commonly administered anti-infective drugs tested for possible interference with the binding of our anti-MV-A iNOS mAb to MV-A iNOS spiked into normal human plasma samples were found to have any effect on binding. 


\section{Kaplan-Meier Survical Curves for rHJ mAb Intervention after an $\mathrm{LD}_{80}$ Dose of LPS in Mice}
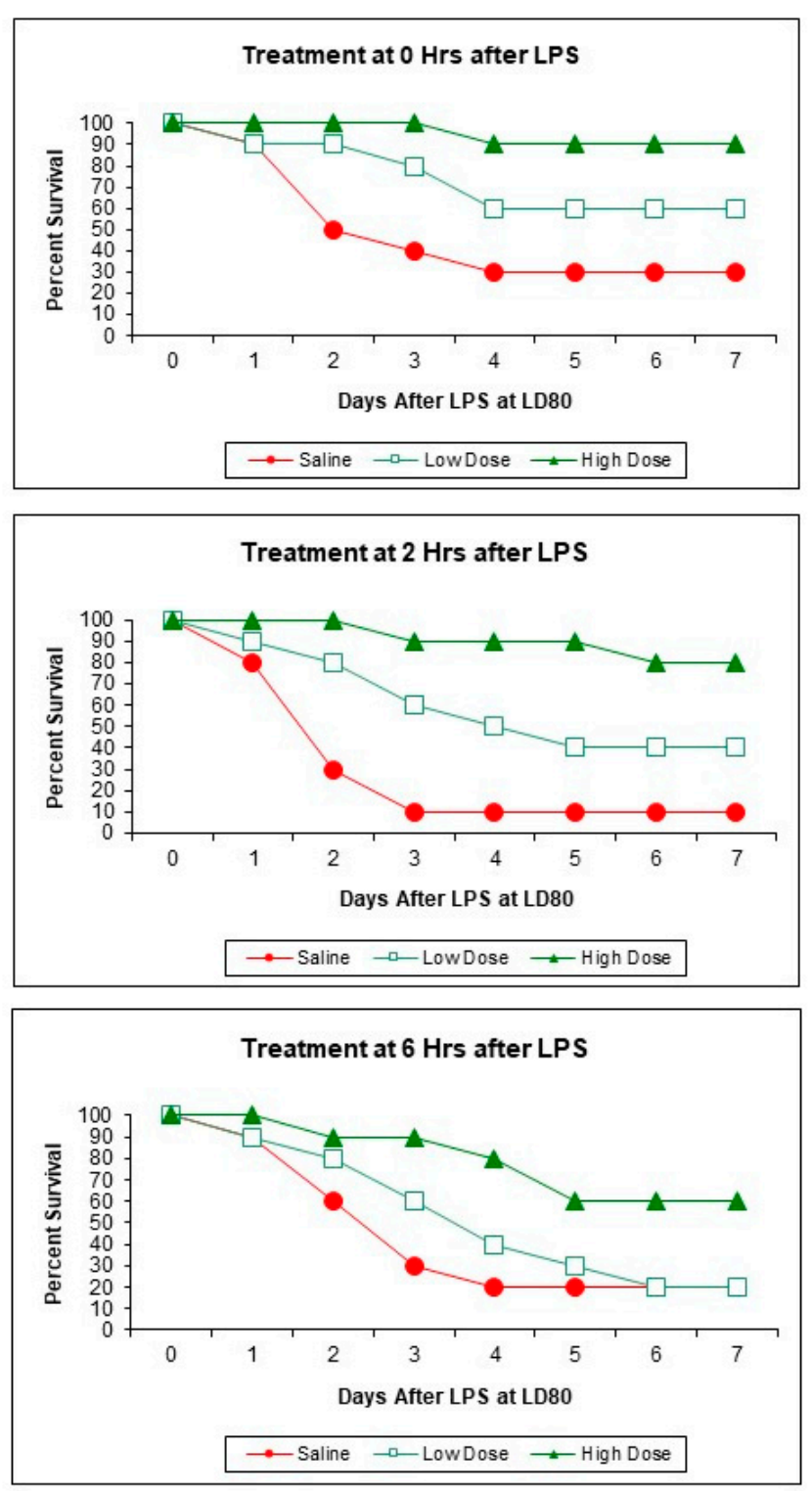

Figure 2. These Kaplan-Meier survival curves demonstrate intervention with both the low dose (125 ng/gm body weight) and the high dose $(1.25 \mu \mathrm{g} / \mathrm{gm}$ body weight) of $\mathrm{rHJ} \mathrm{mAb}$ was effective at rescuing the mice from death by sepsis as compared with the saline control group. The earlier $\mathrm{rHJ} \mathrm{mAb}$ was administered and the higher the dose given, the more effective it was. Similar results were also obtained when an $\mathrm{LD}_{80}$ dose of $\mathrm{TNF} \alpha$ or an $\mathrm{LD}_{80}$ dose of MV-A iNOS was given IV as the challenge.

\section{Discussion}

Our prior data $[6-8,33]$ demonstrate that what occurs in sepsis is aberrant apoptosis (Figure 3) leading to secondary necrosis of cells induced to produce iNOS, to the release into the circulatory system of microvesicle-associated iNOS, and ultimately to the lifethreatening sepsis cascade. Our discovery of the release of microvesicles containing iNOS into blood has been confirmed for septic humans [30,31] and septic rats [32]. After the circulating iNOS-containing microvesicles are isolated, they have been shown by us $[8,33]$ and other investigators to cause cell damage [30], organ damage and dysfunction [31], and death [32]. The left-hand side of the illustration depicts a cell that has been induced 
by the "inflammatory cytokine storm" to make iNOS. The red dashed line indicates that macrophages (Mø) do not recognize this cell as apoptotic: either the cell may not mark itself properly or the macrophages may not recognize the markings properly or there might be a local depletion of macrophages and others could not be recruited in fast enough to scavenge this induced, apoptotic cell. Thus, this apoptotic cell is not properly scavenged by a macrophage.

\section{Aberrant Apoptosis Leads to Secondary Necrosis,}

\section{iNOS-containing Microvesicles, and Sepsis}

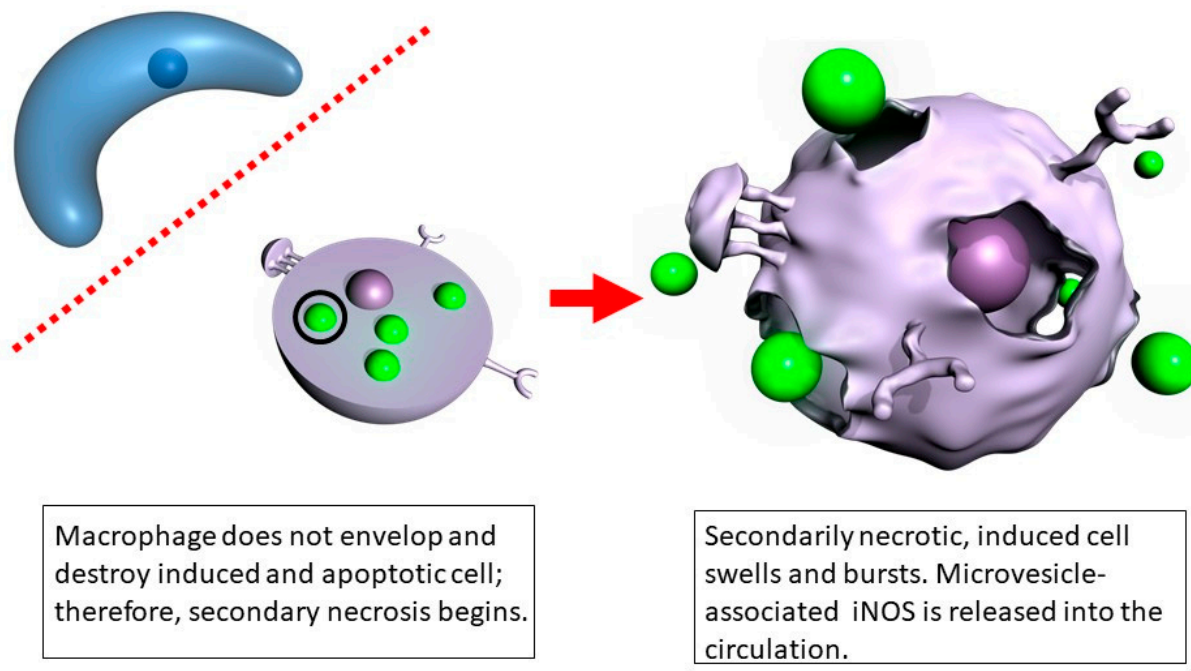

Figure 3. Published data by our team $[6-8,33]$ demonstrate that what triggers sepsis is aberrant apoptosis that leads to secondary necrosis of cells induced to produce iNOS, to the release into the circulatory system of microvesicle-associated iNOS, and ultimately to the life-threatening sepsis cascade. This is a new pathophysiological pathway that was recently discovered and confirmed for the sepsis pathology. The left-hand side of the illustration depicts a cell that has been induced by the inflammatory cytokine storm to make iNOS. The red dashed line indicates that macrophages (Mø) do not recognize this cell as apoptotic. Thus, this induced apoptotic cell is not properly scavenged by a macrophage and instead undergoes secondary necrosis, which is depicted in the right-hand side of this illustration. The secondarily necrotic, induced cells swell, burst, and release their cellular contents into the circulatory system, including iNOS-containing microvesicles (depicted as extracellular green balls).

The question is then, "What happens to this cell?" The answer is the induced, apoptotic cell undergoes secondary necrosis, which is now depicted in the right-hand side of this illustration. The secondarily necrotic, induced cells swell, burst, and release their cellular contents into the blood, and the iNOS enzyme contained in the circulating microvesicles is then delivered as cargo to receiver cells at distal sites in the body (Figure 4).

While the iNOS-containing microvesicles are in the circulatory system, the iNOS is an inactive enzyme because two of its required cofactors are not present in plasma. Our data and the data of other investigators show that these circulating microvesicles lodge onto or bind to the surface of cells and are then internalized into the receiver cells. These processes have been comprehensively described for circulating extracellular microvesicles in other human diseases [34-37]. Once a microvesicle containing iNOS is intercalated into a receiver cell, the MV-A iNOS becomes an active enzyme since it has all of its required substrates and cofactors. However, it is now a component of a cell that has never been induced, it is in an inappropriate location, and the receiver cell is out of normal cellular regulation. Once active, the iNOS enzyme produces toxic quantities of nitric oxide that results in the death 
of that cell. Damage to cardiomyocytes leads to the hemodynamic collapse of the heart [31]. Damage to the blood-brain barrier, the tight junctions of the intestine, the glomerular filtration units of the kidney, and the capillary beds of the circulatory system leads to leakage through these barrier structures. When a receiver cell takes up the circulating microvesicles containing iNOS at one of these locations, the internalized and active iNOS produces enough nitric oxide $\left(\mathrm{NO}^{-}\right)$to kill that cell. Thus, a microperforation is formed in the barrier through which leakage can occur. Microperforations in the blood-brain barrier result in plasma leaking into the brain and to the neurological symptoms associated with sepsis. Microperforations in the tight junctions of the intestines lead to leakage from the lumen of the intestine into the circulatory system and result in bacteremia and/or endotoxemia. Microperforations in the kidneys' glomerular filtration units result in plasma proteins leaking into the urine and in renal failure. Microperforations in the capillary beds results in capillary leak syndrome, including leakage into the interstitial space and an inability to maintain blood pressure. These are the classic hallmark symptoms of sepsis, severe sepsis, and septic shock caused by the circulating MV-A iNOS. This is a new pathway for sepsis that was recently discovered and confirmed.

\section{Circulating Microvesicle-Associated iNOS Causes the Sepsis Cascade}
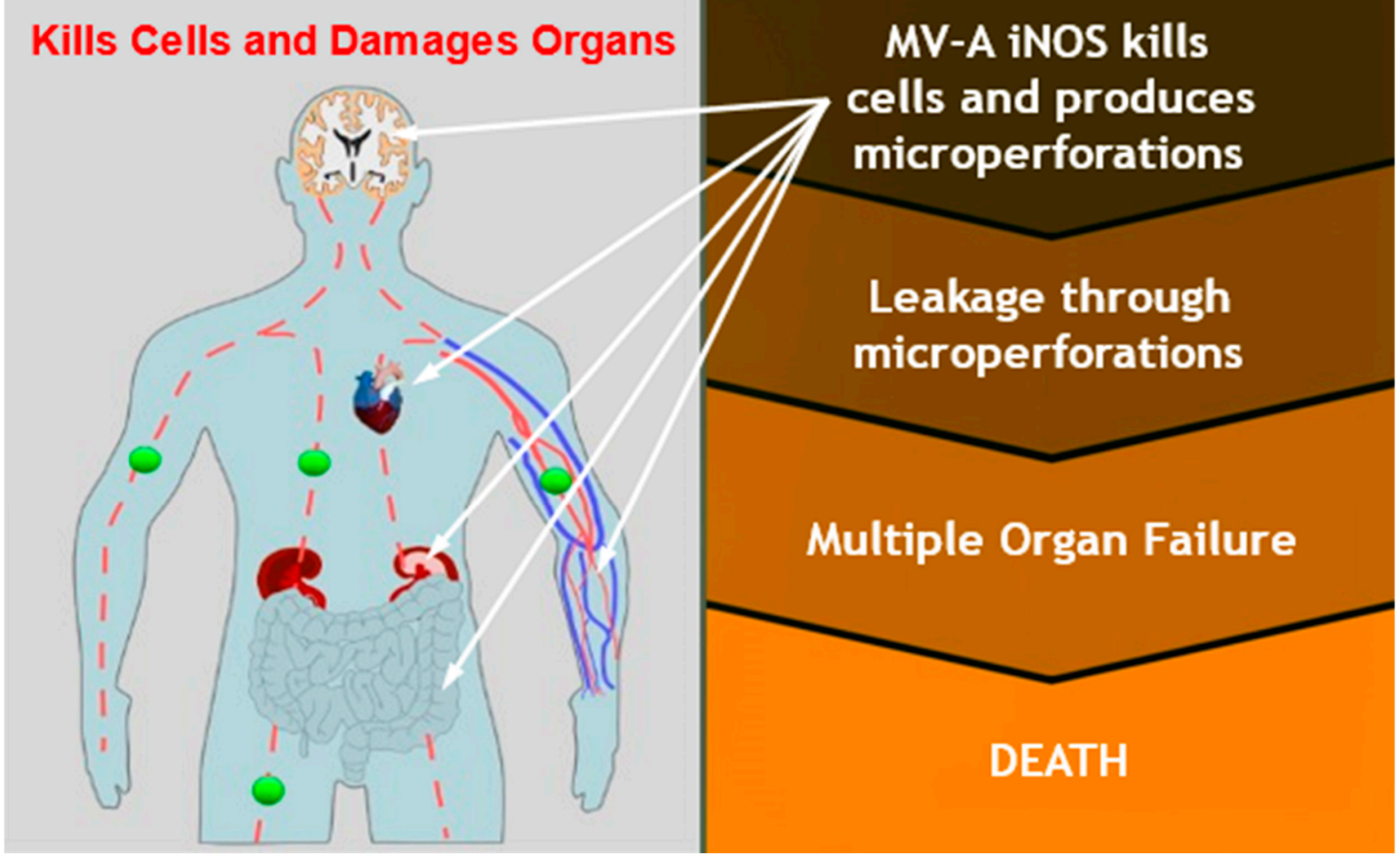

Figure 4. This illustration shows the causative role that microvesicle-associated iNOS (MV-A iNOS), shown as green balls, plays in sepsis. Once the MV-A iNOS is delivered as cargo contained in circulating microvesicles to receiver cells at distal sites in the body, the active iNOS enzyme is internalized into the receiver cells, where it produces toxic quantities of nitric oxide. This kills the receiver cell, which produces microperforations in barrier structures that then leak, and it also damages the myocardium of the heart, which leads to hemodynamic collapse and death.

The ability to stop the delivery of the MV-A iNOS to receiver cells with an in vivo neutralizing immunotherapeutic drug, such as our $\mathrm{rHJ} \mathrm{mAb}$, should be rigorously investigated because of its potential to meet this huge unmet medical need, to save lives worldwide, and to save healthcare systems billions of dollars annually. 
To test whether or not commonly administered anti-infective drugs might interfere with the binding of our anti-MV-A iNOS mAb to MV-A iNOS in plasma, seven different anti-infectives were tested at the plasma concentration recommended in the package insert for each drug, assuming the drug was being administered to a $50 \mathrm{~kg}$ person with a plasma volume of $1.9 \mathrm{~L}$. No effect on binding was observed, which is in agreement with the published literature for these anti-infective drugs' interactions with other immunotherapeutics.

\section{Conclusions}

Circulating MV-A iNOS is a validated new immunotherapeutic target for treating sepsis in three different mouse models of sepsis. Kaplan-Meier survival curves demonstrate that the effectiveness of each recombinant humanized anti-MV-A iNOS mAbs is dose- and time-dependent. Recombinant humanized $\mathrm{J} \mathrm{mAb}(\mathrm{rHJ} \mathrm{mAb})$ can rescue up to $80 \%$ of the challenged animals from death by sepsis if administered early in an episode of sepsis. Our candidate $\mathrm{rHJ} \mathrm{mAb}$ immunotherapeutic to treat sepsis should rapidly be made available to treat the more than 50 million annual cases of sepsis, including septic COVID-19 patients, since almost all COVID-19 fatalities are caused by viral sepsis [9-11].

Author Contributions: Conceptualization, R.J.W. and D.S.W.; methodology, R.J.W., R.M.S. and D.S.W.; software, D.S.W.; validation, R.J.W. and D.S.W.; formal analysis, R.J.W., R.M.S. and D.S.W.; investigation, R.J.W., R.M.S. and D.S.W.; resources, R.J.W.; data curation, R.J.W. and D.S.W.; writingoriginal draft preparation, R.J.W.; writing - review and editing, R.M.S. and D.S.W.; visualization, D.S.W.; supervision, R.J.W.; project administration, R.J.W.; funding acquisition, R.J.W. All authors have read and agreed to the published version of the manuscript.

Funding: All studies reported in this article were funded exclusively by Research \& Diagnostic Antibodies.

Institutional Review Board Statement: All animal studies were reviewed and approved by R\&D Antibodies' Institutional Animal Care and Use Committee (IACUC) and were within the US Department of Agriculture guidelines for animal care.

Informed Consent Statement: Not Applicable.

Data Availability Statement: The data presented in this study are available on request from the corresponding author. No large data sets were developed during these studies.

Conflicts of Interest: R.J.W. and D.S.W. are both paid executives and partial owners of Research \& Diagnostic Antibodies, the sponsor of the studies reported in this article. R.M.S. reports no conflicts of interest.

\section{References}

1. Webber, R.J.; Rodriguez, J.G.; Webber, D.S.; Dunnebacke, T.H. Development, Characterization, and Epitope Mapping of a Panel of Twenty-Four Monoclonal Antibodies Specific for Human Inducible Nitric Oxide Synthase. Hybridoma 2005, 24, 6-13. [CrossRef] [PubMed]

2. Rudd, K.E.; Johnson, S.C.; Agesa, K.M.; Shackelford, K.A.; Tsoi, D.; Kievlan, D.R.; Colombara, D.V.; Ikuta, K.S.; Kissoon, N.; Finfer, S.; et al. Global, regional, and national sepsis incidence and mortality, 1990-2017: Analysis for the Global Burden of Disease Study. Lancet 2020, 395, 200-211. [CrossRef]

3. Singer, M.; Deutschman, C.S.; Seymour, C.W.; Shankar-Hari, M.; Annane, D.; Bauer, M.; Bellomo, R.; Bernard, G.R.; Chiche, J.-D.; Coopersmith, C.M.; et al. The Third International Consensus Definitions for Sepsis and Septic Shock (Sepsis-3). JAMA 2016, 315, 801-810. [CrossRef]

4. Marshall, J.C. Why have clinical trials in sepsis failed? Trends Mol. Med. 2014, 20, 195-203. [CrossRef]

5. Cavaillon, J.; Singer, M.; Skirecki, T. Sepsis therapies: Learning from 30 years of failure of translational research to propose new leads. EMBO Mol. Med. 2020, 12, e10128. [CrossRef] [PubMed]

6. Webber, R.J.; Dunnebacke, T.H. Inducible nitric oxide synthase is an early plasma biomarker for the onset of sepsis. In Proceedings of the 43rd Interscience Conference on Antimicrobial Agents and Chemotherapy, Chicago, IL, USA, 14-17 September 2003; ISBN 1555812848.

7. Webber, R.J.; Sweet, R.M.; Webber, D.S. Inducible Nitric Oxide Synthase in Circulating Microvesicles: Discovery, Evolution, and Evidence as a Novel Biomarker and the Probable Causative Agent for Sepsis. J. Appl. Lab. Med. 2019, 3, 698-711. [CrossRef]

8. Webber, R.J.; Dunnebacke, T.H.; Webber, D.S. Neutralization in vivo of particulate iNOS with humanized anti-iNOS mAbs rescues mice from death by sepsis. In Proceedings of the 46th Interscience Conference on Antimicrobial Agents and Chemotherapy, San Francisco, CA, USA, 27-30 September 2006; ISBN 1555814093. 
9. Yataco, A.O.C.; Simpson, S.Q. Coronavirus Disease 2019 Sepsis. Chest 2020, 158, 1833-1834. [CrossRef]

10. Three Major Scientific Societies Confirm Link between SARSCoV-2 and Sepsis, Which Causes Vast Majority of COVID-19 Deaths. ESICM Joint Statement. July 2021. Available online: https://www.esicm.org/wp-content/uploads/2021/06/PressRelease_ SepsisandCOVID-19_JointStatement.pdf (accessed on 15 July 2021).

11. European Society of Intensive Care Medicine (ESICM); Global Sepsis Alliance (GSA); Society of Critical Care Medicine (SCCM). Reducing the global burden of sepsis: A positive legacy for the COVID-19 pandemic? Intensiv. Care Med. 2021, 47, 733-736. [CrossRef]

12. Buchman, T.G.; Simpson, S.Q.; Sciarretta, K.L.; Finne, K.P.; Sowers, N.; Collier, M.; Chavan, S.; Oke, I.; Pennini, M.E.; Santhosh, A.; et al. Sepsis Among Medicare Beneficiaries: 1. The Burdens of Sepsis, 2012-2018. Crit. Care Med. 2020, 48, 276-288. [CrossRef] [PubMed]

13. Buchman, T.G.; Simpson, S.Q.; Sciarretta, K.L.; Finne, K.P.; Sowers, N.; Collier, M.; Chavan, S.; Oke, I.; Pennini, M.E.; Santhosh, A.; et al. Sepsis Among Medicare Beneficiaries: 2. The Trajectories of Sepsis, 2012-2018. Crit. Care Med. 2020, 48, 289-301. [CrossRef] [PubMed]

14. Buchman, T.G.; Simpson, S.Q.; Sciarretta, K.L.; Finne, K.P.; Sowers, N.; Collier, M.; Chavan, S.; Oke, I.; Pennini, M.E.; Santhosh, A.; et al. Sepsis Among Medicare Beneficiaries: 3. The Methods, Models, and Forecasts of Sepsis, 2012-2018. Crit. Care Med. 2020, 48, 302-318. [CrossRef]

15. Schmid, A.; Burchardi, H.; Clouth, J.; Schneider, H. Burden of illness imposed by severe sepsis in Germany. Eur. J. Health Econ. 2002, 3, 77-82. [CrossRef] [PubMed]

16. Iwashyna, T.J.; Ely, E.W.; Smith, D.M.; Langa, K. Long-term Cognitive Impairment and Functional Disability Among Survivors of Severe Sepsis. JAMA 2010, 304, 1787-1794. [CrossRef] [PubMed]

17. Shah, F.; Pike, F.; Alvarez, K.; Angus, D.; Newman, A.B.; Lopez, O.; Tate, J.; Kapur, V.; Wilsdon, A.; Krishnan, J.A.; et al. Bidirectional Relationship between Cognitive Function and Pneumonia. Am. J. Respir. Crit. Care Med. 2013, 188, 586-592. [CrossRef] [PubMed]

18. Angus, D.C.; Van Der Poll, T. Severe Sepsis and Septic Shock. N. Engl. J. Med. 2013, 369, 840-851. [CrossRef] [PubMed]

19. Seymour, C.W.; Gesten, F.; Prescott, H.; Friedrich, M.E.; Iwashyna, T.J.; Phillips, G.S.; Lemeshow, S.; Osborn, T.; Terry, K.M.; Levy, M.M. Time to Treatment and Mortality during Mandated Emergency Care for Sepsis. N. Engl. J. Med. 2017, 376, 2235-2244. [CrossRef] [PubMed]

20. Martin, G.S.; Mannino, D.; Eaton, S.; Moss, M. The Epidemiology of Sepsis in the United States from 1979 through 2000. N. Engl. J. Med. 2003, 348, 1546-1554. [CrossRef]

21. Liu, V.; Escobar, G.J.; Greene, J.D.; Soule, J.; Whippy, A.; Angus, D.C.; Iwashyna, T.J. Hospital Deaths in Patients with Sepsis From 2 Independent Cohorts. JAMA 2014, 312, 90-92. [CrossRef]

22. Rhee, C.; Dantes, R.; Epstein, L.; Murphy, D.J.; Seymour, C.W.; Iwashyna, T.J.; Kadri, S.S.; Angus, D.C.; Danner, R.L.; Fiore, A.E.; et al. Incidence and Trends of Sepsis in US Hospitals Using Clinical vs. Claims Data, 2009-2014. JAMA 2017, 318, 1241-1249. [CrossRef]

23. Donovan, K.; Shah, A.; Day, J.; McKechnie, S.R. Adjunctive treatments for the management of septic shock-A narrative review of the current evidence. Anaesthesia 2021, 76, 1245-1258. [CrossRef] [PubMed]

24. Wang, H.E.; Szychowski, J.M.; Griffin, R.; Safford, M.M.; Shapiro, N.I.; Howard, G. Long-term mortality after community-acquired sepsis: A longitudinal population-based cohort study. BMJ Open 2014, 4, e004283. [CrossRef]

25. Perl, T.M. Long-Term Survival and Function after Suspected Gram-Negative Sepsis. JAMA 1995, 274, 338-345. [CrossRef]

26. Levy, M.M.; Fink, M.P.; Marshall, J.C.; Abraham, E.; Angus, D.; Cook, D.; Cohen, J.; Opal, S.M.; Vincent, J.-L.; Ramsay, G. 2001 SCCM/ESICM/ACCP/ATS/SIS International Sepsis Definitions Conference. Crit. Care Med. 2003, 31, 1250-1256. [CrossRef] [PubMed]

27. Simpson, S.Q. SIRS in the Time of Sepsis-3. Chest 2018, 153, 34-38. [CrossRef] [PubMed]

28. Takauji, S.; Hayakawa, M.; Fujita, S. A Nationwide Comparison between Sepsis-2 and Sepsis-3 Definition in Japan. J. Intensiv. Care Med. 2020, 35, 1389-1395. [CrossRef] [PubMed]

29. Seymour, C.W.; Liu, V.X.; Kahn, J.M.; Shankar-Hari, M.; Singer, M.; Deutschman, C.S.; Escobar, G.J.; Angus, D.C.; Iwashyna, T.J.; Brunkhorst, F.M.; et al. Assessment of Clinical Criteria for Sepsis: For the Third International Consensus Definitions for Sepsis and Septic Shock (Sepsis-3). JAMA 2016, 315, 762-774. [CrossRef]

30. Gambim, M.H.; de Oliveira do Carmo, A.; Marti, L.; Veríssimo-Filho, S.; Lopes, L.R.; Janiszewski, M. Platelet-derived exosomes induce endothelial cell apoptosis through peroxynitrite generation: Experimental evidence for a novel mechanism of septic vascular dysfunction. Crit. Care 2007, 11, R107. [CrossRef]

31. Azevedo, L.C.; Janiszewski, M.; Pontieri, V.; Pedro, M.A.; Bassi, E.; Tucci, P.J.; Laurindo, F.R. Platelet-derived exosomes from septic shock patients induce myocardial dysfunction. Crit. Care 2007, 11, R120. [CrossRef]

32. Mortaza, S.; Martinez, M.C.; Baron-Menguy, C.; Burban, M.; de la Bourdonnaye, M.; Fizanne, L.; Pierrot, M.; Calès, P.; Henrion, D.; Andriantsitohaina, R.; et al. Detrimental hemodynamic and inflammatory effects of microparticles originating from septic rats. Crit. Care Med. 2009, 37, 2045-2050. [CrossRef]

33. Webber, R.J.; Webber, D.S. Method of Effecting a Mammalian Model of Sepsis, Severe Sepsis, or Septic Shock. PCT Application \#WO 2007/024568, 16 August 2006. 
34. Shah, R.; Patel, T.; Freedman, J.E. Circulating Extracellular Vesicles in Human Disease. N. Engl. J. Med. 2018, 379, 958-966. [CrossRef]

35. Yáñez-Mó, M.; Siljander, P.R.-M.; Andreu, Z.; Zavec, A.B.; Borràs, F.E.; Buzas, E.I.; Buzas, K.; Casal, E.; Cappello, F.; Carvalho, J.; et al. Biological properties of extracellular vesicles and their physiological functions. J. Extracell. Vesicles 2015, 4, 27066. [CrossRef] [PubMed]

36. Jansen, F.; Nickenig, G.; Werner, N. Extracellular Vesicles in Cardiovascular Disease. Circ. Res. 2017, 120, 1649-1657. [CrossRef] [PubMed]

37. Gopal, S.K.; Greening, D.W.; Rai, A.; Chen, M.; Xu, R.; Shafiq, A.; Mathias, R.A.; Zhu, H.-J.; Simpson, R.J. Extracellular vesicles: Their role in cancer biology and epithelial-mesenchymal transition. Biochem. J. 2017, 474, 21-45. [CrossRef] [PubMed] 